\title{
вмJ Global Health Quality improvement in maternal and newborn healthcare: lessons from programmes supported by the German development organisation in Africa and Asia
}

\author{
Sophie Goyet, ${ }^{\oplus 1}$ Valerie Broch-Alvarez, ${ }^{2}$ Cornelia Becker ${ }^{3}$
}

To cite: Goyet S,

Broch-Alvarez V, Becker C. Quality improvement in maternal and newborn healthcare: lessons from programmes supported by the German development organisation in Africa and Asia. BMJ Global Health 2019;4:e001562. doi:10.1136/ bmjgh-2019-001562

Handling editor Seye Abimbola

- Additional material is published online only. To view please visit the journal online (http://dx.doi.org/10.1136/ bmjgh-2019-001562).

Received 13 March 2019 Revised 2 July 2019 Accepted 27 July 2019

Check for updates

\section{(c) Author(s) (or their} employer(s)) 2019. Re-use permitted under CC BY-NC. No commercial re-use. See rights and permissions. Published by BMJ.

${ }^{1}$ Independant researcher, Annecy le vieux, France

${ }^{2}$ Health and social protection, Deutsche Gesellschaft für Internationale Zusammenarbeit (GIZ), Kathmandu, Nepal ${ }^{3}$ Maternal and Newborn Care, Deutsche Gesellschaft für Internationale Zusammenarbeit (GIZ), Phnom Penh, Cambodia

Correspondence to Dr Sophie Goyet; sophiegoyet@gmail.com

\section{ABSTRACT}

Improving the quality of maternal and child healthcare (MCH) is a mandatory step on the path to reaching the Sustainable Development Goals and Universal Health Coverage. Quality improvement (QI) in $\mathrm{MCH}$ is a strong focus of the bilateral development cooperation provided by Germany to help strengthen the health systems of countries with high maternal and child mortality rates and/or with high unmet needs for family planning. In this article, we report on the findings of an analysis commissioned by a community of practice on $\mathrm{MCH}$, of Deutsche Gesellschaft für Internationale Zusammenarbeit (GIZ). The objectives were to review the QI interventions implemented through programmes which have received technical assistance from GIZ on behalf of the German Federal Ministry for Economic Cooperation and Development in 14 Asian and African countries, to identify and describe the existing approaches and their results, and finally to draw lessons learnt from their implementation. Our analysis of the information contained in programme documents and reports identified five main methodologies used to improve the quality of care: capacity-building and supervision, governance and regulation, systemic $\mathrm{Ql}$ at facility level, support to infrastructures, and community support. It is difficult to attribute the observed progresses in maternal and neonatal health to a particular agency, programme or intervention. We acknowledge that systemic implementation research embedded within the programmes would facilitate an understanding of the determinants of successful QI interventions, would better assess their effectiveness, and therefore better guide future bilateral aid programmatic decisions.

\section{INTRODUCTION}

Improving the quality of maternal and newborn care remains a priority in today's world. Despite a $29 \%$ reduction in global maternal deaths from 1990 to 2015, up to 289000 women still die annually during pregnancy, childbirth or within 6 weeks of delivery. In addition, 2.6 million newborns

\section{Summary box}

- There is a need for bilateral development agencies to understand which quality improvement strategies work better, which strategies do not work, how and why, in order to rationalise their programming decisions.

- Five main approaches are taken to improve the quality of maternal and child healthcare (MCH) in programmes supported by the German technical bilateral cooperation agency (Deutsche Gesellschaft für Internationale Zusammenarbeit), but the available programme documentation alone does not allow discussing the effectiveness of these strategies.

- Systemic implementation research embedded within cooperation agencies' programmes could help better appraise the facilitating and impeding factors of each quality improvement approach and to evaluate their cost-effectiveness.

- We recommend the use of the recent WHO guidance on how to report on sexual, reproductive, maternal, neonatal child and adolescent health programmes to systematically document MCH programmes and draw lessons learnt.

die annually within their first month of life, mainly as a result of complications such as prematurity and low birth weight, birth asphyxia and newborn infections, often due to the quality of care mothers and babies receive during birth and the first day of life. ${ }^{2}$

A reduction of maternal and newborn mortality has been linked to the current increase in coverage of antenatal care services, in-facility deliveries and skilled birth attendance. ${ }^{1}$ However, field evidence suggests that 'available services in many countries are of poor quality'. ${ }^{3}$ A significant proportion of maternal and newborn mortalities sadly occur in health facilities ${ }^{4}$ that cannot always guarantee a care that is 'effective, safe, 
people-centred, delivering services that are timely, equitable, integrated, and efficient, ${ }^{56}$ as recommended by the World Health Organisation (WHO) ${ }^{78}$ Moreover, with the ambitious Sustainable Development Goals (SDGs) to reach by 2030, it becomes clear that efforts should now be directed towards better quality of care, in addition to the further expansion of health services coverage. ${ }^{9-11}$

The German government has long been committed to strengthen health systems worldwide, with a focus on maternal and child healthcare (MCH) ${ }^{12}$ In 2010, as global statistics showed that maternal, neonatal and child death rates were not decreasing enough to meet the Millennium Development Goals, Germany and the other G8 countries founded the 'G8 Muskoka Initiative'. ${ }^{13}$ They committed to mobilise $\$ 5$ billion of additional funding over the period 2010-2015 towards maternal, newborn and child health, in addition to their regular annual contributions $^{14}$ (online supplementary file 1). In 2011, as a contribution to the Muskoka Initiative, the German Federal Ministry for Economic Cooperation and Development (BMZ) launched a bilateral initiative on 'RightsBased Family Planning and Maternal Health' which, by 2017, has reached a total of 34 countries with high maternal and child mortality rates and/or high unmet needs for family planning. ${ }^{1516}$ In 2015 , Germany pledged to maintain its financial commitment to provide at least $€ 380$ million annually in support of the SDGs, ${ }^{16}$ being the third largest bilateral donor for global health. ${ }^{17}$

As quality of care has become an essential global priority, ${ }^{10}$ funding agencies would benefit from a better understanding of what works, where, how and why, in order to rationalise their programming decisions. To our knowledge only one bilateral cooperation agency, the US Agency for International Development (USAID), has recently published a peer-reviewed analysis of their quality improvement (QI) programmes. ${ }^{18}$ In this paper, we briefly describe the approaches supported by the Deutsche Gesellschaft für Internationale Zusammenarbeit (GIZ) - which channels the German bilateral technical cooperation on behalf of BMZ-to improve the quality of care in $\mathrm{MCH}$ in 14 African and Asian countries and discuss the lessons learnt during this review.

The review has been commissioned by a technical working group established by the GIZ Community of Practice (CoP) consisting of technical staff working in the field of quality of care in $\mathrm{MCH}$ for the German development cooperation. This CoP promotes the exchange of knowledge and experience on health and social protection across countries and programmes implemented by GIZ. In 2017 and 2018, all programmes' documents shared by the 14 country teams were analysed by two public health consultants, using Rowe et al $\mathrm{s}^{19}$ definitions of strategies to improve healthcare providers' practice. Data collected during the initial analysis were later reviewed, to present the various QI interventions implemented in GIZ-supported programmes according to the classification used in the latest WHO Handbook for National Quality Policy and Strategy. ${ }^{8}$ The review also included case studies developed by country teams of Cambodia, Nepal and Tanzania using recent WHO reporting standards..$^{20}$ Most programmes considered in this review started in the early 2010s (figure 1).

\section{MAIN QUALITY IMPROVEMENT APPROACHES IMPLEMENTED}

All programmes launched before 2015 had the objective to improve sexual, reproductive health and rights (SRHR) and family planning. More recent programmes
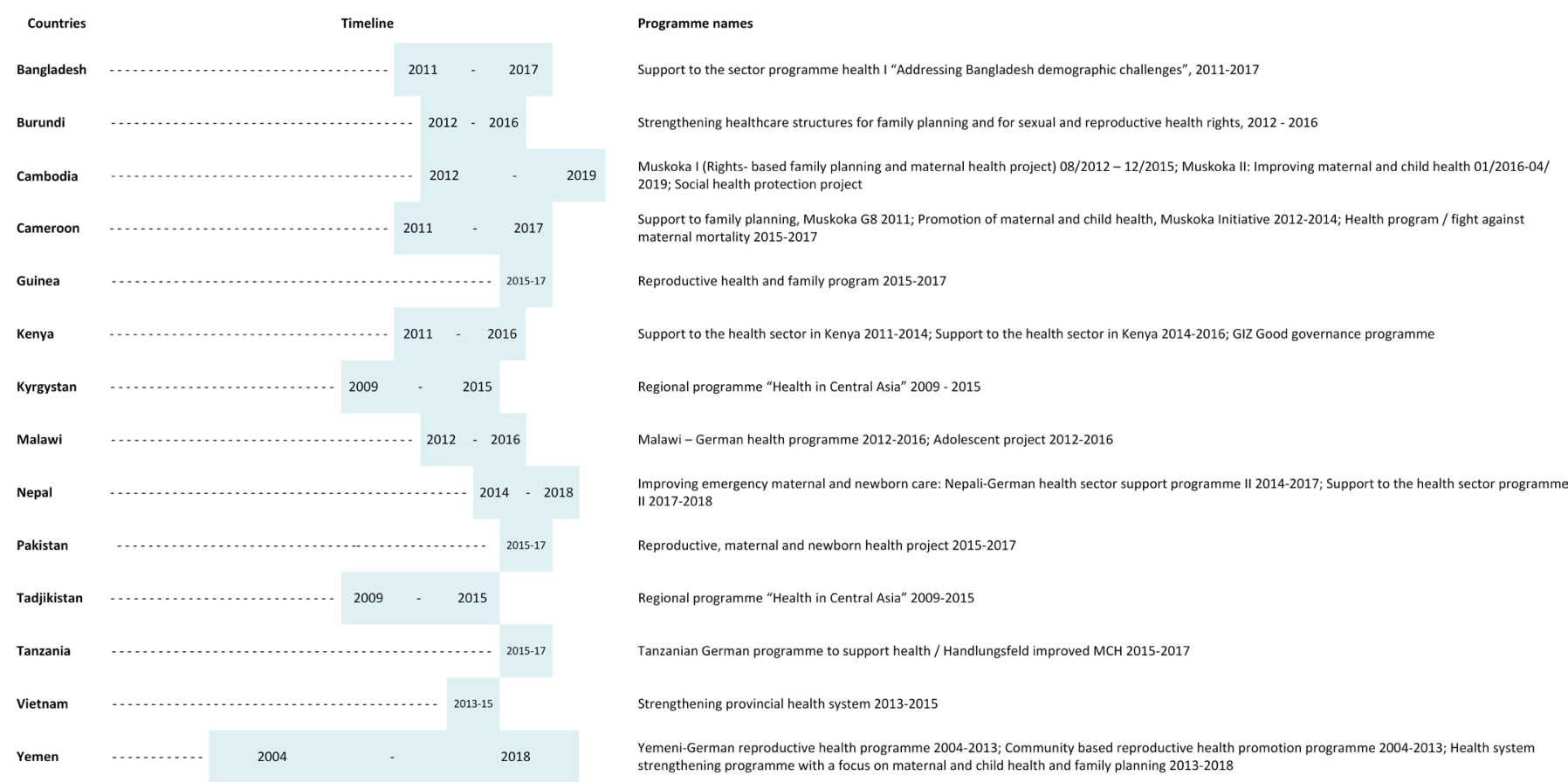

Figure 1 GIZ-supported programmes included in this review. GIZ, Deutsche Gesellschaft für Internationale Zusammenarbeit. 
have concentrated on the improvement of emergency obstetrical and newborn care (EmONC) services (12 of 14 countries), emergency referral services (9 f 14 countries) and newborn care services (9 of 14 countries). All programmes have been implemented following a multilevel, integrative and systemic approach. This approach combines interventions at various levels of the health system. Technical assistance is usually provided at the macro-level, to define or review policies, standards and guidance for strengthening the quality of healthcare. For instance in Nepal, support was given to establish a new 'Quality Assessment and Regulation Division' at the Ministry of Health and Population to strengthen the quality assurance system in the new Federal context. This division reviewed the status of all treatment protocols and guidelines and established a steering committee to process for their revision. Meanwhile, at the micro-level, the Nepal country team trained health professionals in midwifery skills through inservice training alongside mentoring programmes.

\section{INTERVENTIONS AIMING TO IMPROVE THE SYSTEMS' ENVIRONMENT \\ Clinical governance}

In all reviewed countries, the German development cooperation has worked on improving the countries' capacity for clinical governance (table 1. Examples of interventions are displayed in online supplementary file 2). In many countries (Bangladesh, Cambodia, Kenya, Malawi, Nepal, Yemen and Tanzania), technical expertise has also been provided to help the creation or the strengthening of national regulating or coordinating bodies focusing on quality of care, such as national steering committees. In many countries as well, technical and financial support to national midwives' associations has also been provided to strengthen their legal basis for regulation, as well as their competencies in human resource management and fundraising.

\section{Accreditation}

Moreover, country teams have established national quality accreditation systems in 6 out of 14 countries. The process includes the setting of official quality standards towards which the health facilities strive for. After a self-assessment or an external evaluation, an accrediting organisation certifies that the health facility has met the standards and has implemented measures for sustainable improvement. Additionally, capacity development was provided to national accreditation agencies, to peer assessors/surveyors and to participating health facilities.

\section{Training and supervision of workforce}

Capacity-building and supportive supervision are two types of interventions aiming to improve the system's environment widely implemented in GIZ-supported programmes.

Healthcare workers' pre-service and in-service education, coaching, mentoring and supervision are other
QI strategies widely supported by GIZ as a continuum of human resource capacity-building process. In particular, in recent years there have been tremendous efforts to develop the midwifery workforce, both at pre-service and in-service levels in 9 of the 14 countries reviewed (table 1). In-service training of obstetricians, anaesthesiologists and intensive care medical doctors has been a key approach used in Kyrgyzstan and Tajikistan to improve EmONC through a regional approach involving other neighbouring countries as well. In-service training has been provided to health workers in several countries also about SRHR issues and services.

Coaching and mentoring were extensively implemented to improve staff performance and confidence (table 1). Both coaching and mentoring are flexible training methods that can be learnt on the job, although with different objectives. When coaching, the coach, a responsible clinician, enables her students to achieve specific short-term goals by instructing them, while still assuming responsibility for patient care. ${ }^{21}$ Mentoring implies a longer relationship between a mentor and a mentee, based on mutual trust and respect, and true partnership, only possible once confidence is built between them. ${ }^{21}$ Mentoring aims to develop the full potential of the mentee, with benefits to all partners: mentor, mentee and the organisation..$^{22}$ Some programmes have promoted clinical mentoring and the mentoring of the health facility management team to improve the work environment.

Supportive supervision is the last element of this capacity-building continuum implemented in 10 of the 14 countries reviewed (table 1). Supportive supervision is a form of traditional supervision of health staff, where the emphasis is on improving staff performance through encouragement, guidance and follow-up. ${ }^{21}$ It is an interactive and iterative process providing further training opportunities.

\section{INTERVENTIONS AIMING TO IMPROVE CLINICAL CARE Clinical standards}

Technical support was provided to national health institutions for the preparation of policy documents guiding health practices, such as guidelines or standard operation procedures on EmONC in 3 of 14 countries, on referral procedures in 4 countries, and on newborn care and kangaroo mother care in 3 countries.

\section{Collaborative and team-based improvement cycles}

In several programmes, complex systemic processes were promoted to improve the quality of care provided at health facilities.

The 5S-Kaizen-Total Quality Management (TQM) approach has been pioneered by the Japanese cooperation since the $1990 \mathrm{~s},{ }^{23}$ and later implemented through GIZ-supported programmes in Bangladesh, Kenya, Tanzania and Malawi. 5S stands for the starting point of the method: a sequence of activities (Sort, Set, Shine, 
Table 1 Main quality improvement approaches used in GIZ-supported programmes to improve the quality of sexual, reproductive, maternal, newborn, child and adolescents care services targets and places, 2010-2017

\begin{tabular}{|c|c|c|}
\hline Type of intervention & Target & Location \\
\hline \multicolumn{3}{|l|}{ System environment } \\
\hline \multirow[t]{2}{*}{ Clinical governance } & National midwifery associations. & Malawi, Kyrgyzstan, Nepal, Tajikistan and Yemen. \\
\hline & Quality management national bodies. & $\begin{array}{l}\text { Bangladesh, Cambodia, Kenya, Malawi, Yemen and } \\
\text { Tanzania. }\end{array}$ \\
\hline External evaluation and accreditation & Accreditation of health facilities. & $\begin{array}{l}\text { Yemen, Kenya, Kyrgyzstan, Malawi, Tanzania, Tajikistan and } \\
\text { Vietnam. }\end{array}$ \\
\hline \multicolumn{3}{|l|}{ Training and supervision of workforce } \\
\hline Preservice training & For midwives. & Bangladesh, Cameroon, Malawi, Nepal and Tanzania. \\
\hline Inservice training, coaching & $\begin{array}{l}\text { For midwives and other skilled birth } \\
\text { attendants. }\end{array}$ & $\begin{array}{l}\text { Cambodia, Bangladesh, Malawi, Nepal, Tanzania, } \\
\text { Kyrgyzstan, Tajikistan and Yemen. }\end{array}$ \\
\hline \multirow[t]{3}{*}{ Mentoring } & For EmONC teams or CHWs. & $\begin{array}{l}\text { Bangladesh, Cambodia, Kenya, Kyrgyzstan, Nepal, Pakistan, } \\
\text { Vietnam and Yemen. }\end{array}$ \\
\hline & For newborn care providers. & $\begin{array}{l}\text { Bangladesh, Cambodia, Malawi, Nepal, Tajikistan and } \\
\text { Tanzania. }\end{array}$ \\
\hline & For SRHR health workers. & $\begin{array}{l}\text { Cambodia, Guinea, Kenya, Kyrgyzstan, Malawi, Nepal and } \\
\text { Yemen. }\end{array}$ \\
\hline Supportive supervision & For MNC staff. & $\begin{array}{l}\text { Bangladesh, Guinea, Kenya, Kyrgyzstan, Malawi, Nepal, } \\
\text { Tajikistan, Tanzania, Vietnam and Yemen. }\end{array}$ \\
\hline \multicolumn{3}{|l|}{ Improvement in clinical care } \\
\hline \multirow[t]{3}{*}{ Clinical standards, pathways and protocols } & EmONC guidelines. & Kyrgyzstan, Tajikistan and Vietnam. \\
\hline & Referral guidelines. & Kenya, Nepal, Tajikistan and Tanzania. \\
\hline & $\begin{array}{l}\text { Guidelines on newborn care, kangaroo mother } \\
\text { care. }\end{array}$ & Cambodia, Nepal and Tanzania. \\
\hline \multirow[t]{3}{*}{ Collaborative and team-based improvement cycles } & 5S-Kaisen-TQM. & Bangladesh, Kenya, Tanzania and Malawi. \\
\hline & SBM-R. & Nepal. \\
\hline & Quality competition. & Burundi, Guinea, Cameroon, Pakistan and Yemen. \\
\hline Morbidity and mortality reviews & $\begin{array}{l}\text { Maternal, perinatal death surveillances or } \\
\text { audits. }\end{array}$ & Kenya, Tanzania, Tajikistan, Kyrgyzstan and Pakistan. \\
\hline \multicolumn{3}{|c|}{ Patient, family and community engagement and empowerment } \\
\hline \multirow[t]{3}{*}{ Formalised community engagement } & Villages and disabled persons. & Cambodia. \\
\hline & $\begin{array}{l}\text { Religious authorities, media and policy- } \\
\text { makers. }\end{array}$ & Kyrgyzstan. \\
\hline & Community health workers. & Yemen and Kenya. \\
\hline \multirow[t]{3}{*}{ Health literacy } & Adolescents. & Bangladesh. \\
\hline & Parents and teachers. & Kyrgyzstan. \\
\hline & Students. & Yemen. \\
\hline \multirow[t]{2}{*}{ Peer support/education } & Adolescents. & Bangladesh and Nepal. \\
\hline & Students. & Malawi. \\
\hline
\end{tabular}

This table does not exhaustively report country partners' activities. Examples of interventions are displayed in the table in online supplementary file 2 . Two case studies presenting the programmes conducted in Nepal and Cambodia are also attached to this article, in online supplementary files 3 and 4.

CHWs, community health workers; EmONC, emergency obstetrical and newborn care; GIZ, Deutsche Gesellschaft für Internationale Zusammenarbeit; MNC, Maternal, Newborn and Child care; SBM-R, Standards-Based Management and Recognition; 5S-Kaisen-TQM, 5S-Kaisen-Total Quality Management; SRHR, sexual and reproductive health rights.

Standardise and Sustain) to improve the work environment. The 'Kaizen' step mobilises group-solving and cocreation techniques in repetition cycles, involving both clinicians and health facility management teams, to identify the weakest points of the quality management, and to find and implement local solutions. The TQM aspect looks at the management of medicines and equipment, and at other elements which may increase patients' and providers' satisfaction. ${ }^{24}$

The Standards-Based Management and Recognition (SBM-R) approach used in Nepal's EmONC mentoring programme aimed at improving the performance of medical, nursing and midwifery staff. Based on the
Deming cycle of Plan-Do-Check-Act, ${ }^{25}$ the concept has been initially developed by Jhpiego in USA-supported programmes. ${ }^{26}$ In GIZ programmes, it was implemented in repeated cycles of four steps: (1) set healthcare performance standards for high quality of care; (2) put these standards into practice through capacity-building techniques; (3) measure performance before, during and after the programme; and (4) recognise and reward achievements.

The 'Quality Competition' implemented in Burundi, Guinea, Cameroon and Pakistan was a voluntary and positive competition between health facilities. ${ }^{27}$ Volunteering health facilities were trained on quality of care concepts, 
Health services

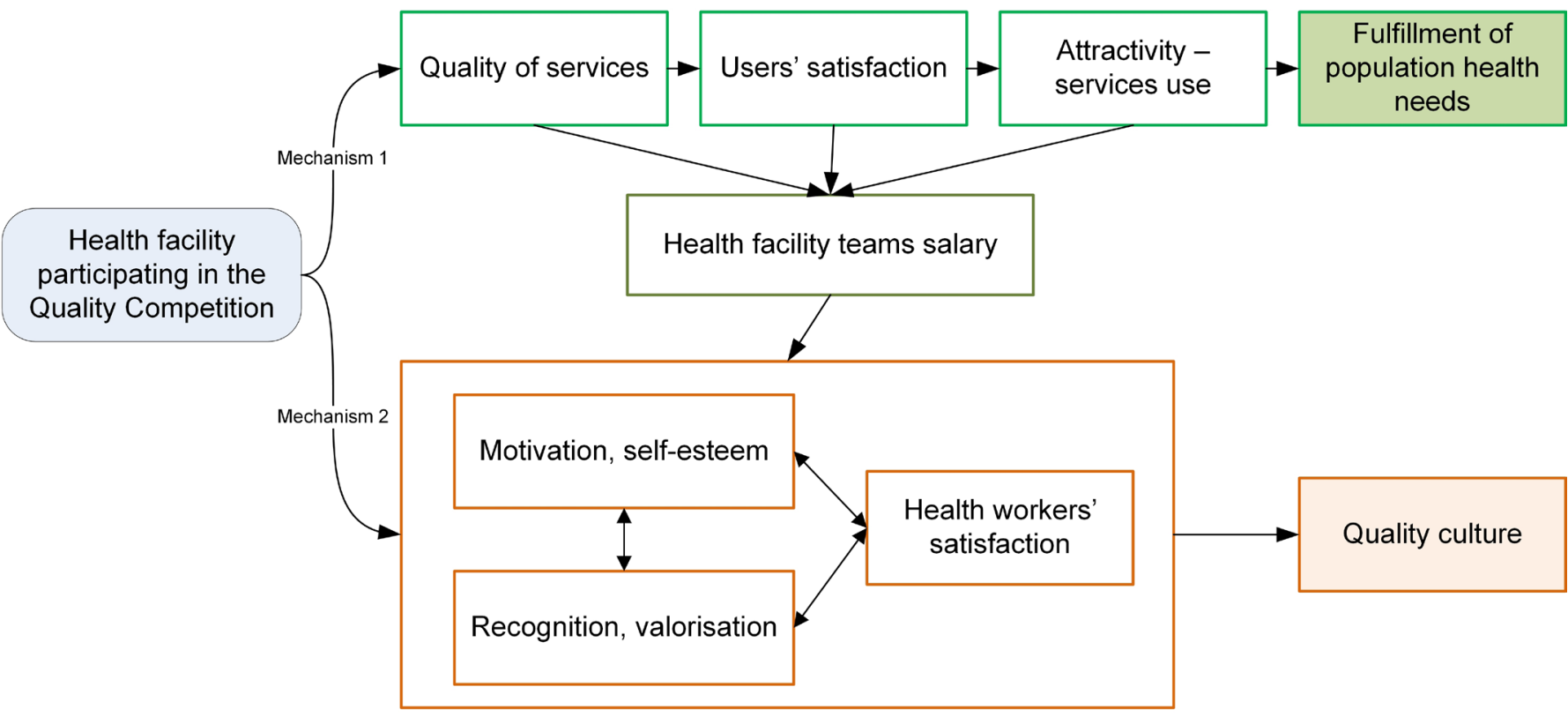

Health service teams

Figure 2 Conceptual framework for the quality competition (QC) in Burundi, adapted from an external mid-term evaluation report. The QC underlying the theory of change is the following: participating in the QC will positively impact both the quality of care provided and the fulfilment of the population health needs by two mechanisms: (1) the quality of care will improve, which will positively affect users' satisfaction and increase the health service use, leading to the fulfilment of the population's needs; and (2) participation in QC will improve healthcare providers' self-esteem, recognition and valorisation, which will increase their satisfaction and participation in the development of a quality culture.

processes and tools. In each participating health facility, an initial situation assessment was conducted by the health facility teams. The teams planned and implemented corrective measures using available means. A final self-assessment was completed, with findings reviewed by an external evaluation team (health authorities and teams from other health facilities). Health facilities were then ranked according to their achievements. Finally, participating health facilities with improved performance were rewarded (figure 2).

\section{Morbidity and mortality reviews}

Finally, support has also been provided to set up or strengthen maternal and perinatal death surveillance or audit programmes in 5 of 14 countries. These programmes aim to improve the reporting of statistics on maternal and perinatal deaths to guide policy-makers', public health managers' and clinicians' responses to avoid future deaths. $^{28}$

\section{INTERVENTIONS AIMING TO ENGAGE AND EMPOWER PATIENTS, FAMILIES AND COMMUNITIES}

Among other QI approaches, community health education or social marketing of health services has been widely used for strengthening the SRHR and family planning. Community awareness campaigns on access and use of family planning and SRHR services have targeted adolescents, disabled persons, religious authorities, media and policy-makers, students, or community health workers, according to the needs. According to the context, various populations have been targeted by health literacy programmes, sometimes through peer education: adolescents, parents, teachers and students.

\section{STRENGTHENING OF HEALTH INFRASTRUCTURES}

Lastly, to a lesser degree, the supported programmes have worked on strengthening health infrastructures such as blood banks, skills and simulation laboratories, neonatal care units, and EmONC sites by providing medical or general equipment, consumables and medicines.

\section{LESSONS LEARNT \\ Tackling the right issues in the right way?}

Our review highlights that GIZ's strategy has been to combine complementary approaches. Technical expertise was provided to ministries of health and other national institutions to develop the national quality management agenda, regulations and programmes, to promote the use of internationally recognised guidance, while at the same time support was given to improve the performance of health workers and the management of health services. This multilevel and integrated approach is supported by recent research that has shown that single interventions are unlikely to achieve important reductions in maternal, newborn and child mortality. ${ }^{29}$ Combining interventions is more effective in improving healthcare practices than implementing them individually. 
Moreover, GIZ support is always provided in coordination with other external development partners, and of course with the ministries of health (MOHs), following a sector-wide approach (SWAp). The aim of the SWAp is to improve aid effectiveness by 'bringing together governments, donors and other stakeholders' in contexts where several health partners are present and play a significant role. $^{30}$

GIZ programmes are usually defined after a project appraisal mission based on government negotiations about health priorities, which combines (1) health data review; (2) consideration of national, international evidence and WHO recommendations; and (3) discussions with the MOH at various levels, other health partners and target groups. Based on this appraisal, a proposal is developed including interventions based on national priorities and policies, and of course which are chosen to complement other health partners and government activities. The proposal would be again discussed with $\mathrm{MOH}$ and other partners before being submitted to the German development funding body.

The review showed that these QI programmes have focused on many factors that critically influence the quality of care. These factors are well described in the scientific literature. ${ }^{31-34}$ They mostly relate to human resources development and to weak referral mechanisms. Health facilities' equipment, logistics, organisation and management are also known to impede the quality of care. Poor health financing (budget allocation and financial barriers for users) is another issue impacting various components of the quality of care. We believe this approach focusing on critical factors is relevant to maximise the impact of QI interventions. We have also observed that the most recent QI programmes aiming to improve EmONC services focus on healthcare providers' performance and on the availability and readiness of services. We recommend this approach since research has shown that most stillbirths and maternal and neonatal deaths are due to complications that could be avoided if high-quality EmONC services were universally available and accessible. ${ }^{49} 35$

We have also shown that in several countries, GIZ supports programmes that aim to strengthen the midwifery workforce. Indeed, midwives have a pivotal part to play in MCH care. As demonstrated by strong research evidence, investment in midwives' education, regulation, management and work environment could avert $80 \%$ of maternal and newborn deaths, including stillbirths. ${ }^{36} 37$ The current orientation towards midwifery seems therefore appropriate and should be sustained. The WHO has recently recognised that optimising the health workforce is critical to accelerate progress towards the SDGs. ${ }^{38}$

\section{Can we measure the success of these quality improvement approaches?}

In line with the global trends, the maternal, neonatal and child mortality rates have dropped between 2000 and 2015 in all countries where these QI programmes have been implemented. ${ }^{2}{ }^{39}$ In 2015 , Vietnam had already achieved the maternal, neonatal and child mortality SDGs, while Tajikistan and Kyrgyzstan had respectively achieved the maternal and child mortality SDGs (table 2).

Table 2 Sustainable development indicators for maternal, neonatal and child mortality in the 14 countries reviewed

\section{Maternal mortality ratio (modelled estimate, per 100000 live births)}

Mortality rate, neonatal (per 1000 live births)
Mortality rate, under-5 (per 1000 live births)

\begin{tabular}{|c|c|c|c|c|c|c|c|c|c|}
\hline \multirow[b]{2}{*}{ Countries } & & & & & & & & & \\
\hline & 2000 & 2015 & $\begin{array}{l}\% \text { Annual } \\
\text { drop }\end{array}$ & 2000 & 2015 & $\begin{array}{l}\% \text { Annual } \\
\text { drop }\end{array}$ & 2000 & 2015 & $\begin{array}{l}\% \text { Annual } \\
\text { drop }\end{array}$ \\
\hline Bangladesh & 399 & 176 & -3.7 & 42.4 & 20.7 & -3.4 & 87.4 & 36.4 & -3.9 \\
\hline Burundi & 954 & 712 & -1.7 & 37.1 & 23.4 & -2.5 & 156.7 & 67.1 & -3.8 \\
\hline Cambodia & 484 & 161 & -4.4 & 35.4 & 16.3 & -3.6 & 107.0 & 32.0 & -4.7 \\
\hline Cameroon & 750 & 596 & -1.4 & 32.9 & 26.5 & -1.3 & 150.3 & 90.1 & -2.7 \\
\hline Guinea & 976 & 679 & -2.0 & 46.7 & 25.0 & -3.1 & 165.4 & 91.7 & -3.0 \\
\hline Kenya & 759 & 510 & -2.2 & 30.8 & 21.8 & -1.9 & 104.5 & 48.7 & -3.6 \\
\hline Kyrgyzstan & 74 & 76 & 0.2 & 21.6 & 12.0 & -3.0 & 49.5 & $\underline{22.3}$ & -3.7 \\
\hline Malawi & 890 & 634 & -1.9 & 39.4 & 24.1 & -2.6 & 171.9 & 61.7 & -4.3 \\
\hline Nepal & 548 & 258 & -3.5 & 40.6 & 22.6 & -3.0 & 81.5 & 36.6 & -3.7 \\
\hline Pakistan & 306 & 178 & -2.8 & 60.1 & 46.3 & -1.5 & 112.6 & 79.5 & -2.0 \\
\hline Tajikistan & 68 & $\underline{32}$ & -3.5 & 28.4 & 15.7 & -3.0 & 87.6 & 35.8 & -3.9 \\
\hline Tanzania & 842 & 398 & -3.5 & 32.7 & 22.0 & -2.2 & 130.4 & 58.3 & -3.7 \\
\hline Vietnam & 81 & 54 & -2.2 & 14.8 & 11.0 & -1.7 & 29.7 & 21.6 & -1.8 \\
\hline Yemen & 440 & 385 & -0.8 & 37.2 & 27.0 & -1.8 & 95.2 & 55.4 & -2.8 \\
\hline
\end{tabular}

Data source: https://data.worldbank.org/. Rates in bold and underlined have reached the Sustainable Development Goals: maternal mortality ratio $<70 / 100$ 000; neonatal mortality rate $<12 / 1000$; under-5 mortality rate $<25 / 1000$. 
However, it is not possible to assess what portion of this progress could be directly attributed to the programmes implemented by GIZ, ${ }^{40}$ although these programmes are regularly evaluated, including assessments performed to the standards of the Organisation for Economic Co-operation and Development. These evaluations have limitations, despite continuous efforts to improve their quality. Programmes' impacts are mostly measured by comparing data collected before and after the interventions, where data were collected by the programme teams 'who know that it is in their benefit to minimize their failures and promote their successes'. ${ }^{19}$ Moreover, it is difficult to articulate the causal pathway between QI interventions, outcomes and impact on targeted populations' health. More independent scientific research, embedded in bilateral cooperation programmes, is needed to measure the effectiveness of the selected QI approaches in terms of impact. ${ }^{41}$

Interestingly, USAID, which reviewed the QI methods used in their programmes in 2015, also concluded that there is a need for more research to assess the effectiveness of QI programmes. ${ }^{18}$ USAID has identified the six QI methods that account for about $80 \%$ of their total spending on quality of care. ${ }^{18}$ Four of these are widely used in GIZ-supported programmes-accreditation, SBM-R, supervision and clinical inservice training. The two other approaches (the Client-Oriented, Provider-Efficient Services (COPE) approach and Collaborative improvement) could fall into what we defined as systemic QI programmes. Rowe et al, who directed the most comprehensive and recent study on QI effectiveness, ${ }^{19}$ stated that 'because of insufficient information about $\mathrm{COPE}^{\circledR}, \mathrm{SBM}-\mathrm{R}$, and accreditation, it was not possible to compare the effectiveness of the six target strategies [promoted by USAID] ${ }^{18}{ }^{18}$ According to Rowe and colleagues, the success of a method or another depends more on its 'suitability to a particular environment than to its technical merits'. ${ }^{19}$

\section{Why and how to strengthen the programmes' documentation?}

The GIZ country teams have to report on their programme progresses, challenges and achievements to both their respective partner country and to the funding ministry, the BMZ. This documentation is shared at various levels of the health sector. In particular, it is shared during the joint health sector annual reviews, which involve the $\mathrm{MOH}$ and the external development partners. The GIZ documentation then serves to inform the health sector for its annual planning and budgeting exercises.

Robust, transparent and comprehensive reporting is therefore vital to understand the programmes' impact, and effectively draw, interpret and build on the lessons learnt during their course. WHO and its research partners have developed a comprehensive tool to guide the reporting of sexual, reproductive, maternal, neonatal child and adolescent health programmes, taking into account the complex conditions in which they are implemented. ${ }^{42}$ During this review, we found that this tool was
Box 1 Example of lessons learnt in Tanzania, Cambodia and Nepal: selected extracts from case studies developed using the WHO template for reporting sexual, reproductive, maternal, neonatal, child and adolescent health

programmes

Tanzania

- The Tanzanian-German Programme to Support Health/Improved Maternal and Child Health Programme 2015-2017, in cooperation with the Ministry of Health, Community Development, Gender Elderly and Children, designed and implemented a comprehensive package to improve maternal and child health service delivery in 209 health facilities in two regions of Tanzania.

- One part of this package focused on a combined supportive supervision and mentoring approach designed according to the newly published national mentorship guidelines.

\section{Lessons learnt (extracts)}

- 'High involvement of stakeholders in planning, implementation and phase-out of the intervention increased local ownership and made sustainability beyond the overall programme term more likely'.

- 'The combination of short, practical training for a high number of health care providers with an intensive mentoring and supportive supervision scheme and the provision of treatment standards and tools increased motivation, confidence and competence of health care providers and the willingness to treat patients respectfully, despite a severe shortage of staff and only small overall changes in the working environment'.

- 'Training and mentoring on basic maintenance and repair of medical equipment for health care providers had positive effects on participants' attitude towards maintenance if the training emphasises on storage, handling and disinfection'.

- '(...) chronic shortage of skilled health care personnel and inadequate pre-service training for nurses with regards to obstetric service delivery constitute the most pertinent risk to the sustainability of results, but also to the overall improvement of maternal and newborn health in Tanzania'.

- 'It seems of utmost importance to promote midwifery training and to scale up the number of skilled birth attendants in Tanzania, if a further reduction in deaths is to be achieved'.

easy to use and effective in facilitating the reflection of our strategies. ${ }^{20}$ To illustrate the WHO tool's effectiveness and the type of lessons learnt that can be drawn from case studies using this WHO standards, we report in box 1 the main lessons learnt in 2018 from the QI programme implemented in Tanzania. The full case studies of Nepal and Cambodia are in online supplementary files 3 and 4 to provide additional examples. We recommend the use of this WHO tool to organisations that need to better understand their underlying implementation challenges, identify their best practices, and opportunities for scaling up or replication in other contexts.

\section{How sustainable are these quality improvement interventions?}

GIZ works on health system strengthening, in the view of achieving the Universal Health Coverage, which requires long-term engagement. GIZ has long-standing relationships with partner countries and has acquired 
both technical and political know-how as well as a deep knowledge of its partner countries. Its programmes are built within national policies and therefore are in line with national goals and objectives. Technical expertise and capacity development are provided, often together with the provision of specific supplies. Moreover, before bilateral support ceases, GIZ develops with its counterparts adapted exit strategies.

Another factor of sustainability is that rather than focusing on single components of health systems, or on the health sector as a silo, GIZ implements programmes which account for the interactions between system components and also address the impact of other sectors, such as education or climate, on the performance of health systems.

Finally, GIZ believes that its multilevel approach, combined with good partner coordination, facilitates the institutionalisation of the implemented QI activities.

\section{CONCLUSION}

Most methodologies used in GIZ-supported programmes to improve the quality of $\mathrm{MCH}$ actually aim to improve the systems' environment that facilitates quality of care and to improve the clinical performance of healthcare providers. Complementary approaches were combined to tackle the QI issues from different angles and at various levels of the health system. The wide variety of approaches can be explained by efforts to adapt the QI strategies to each context, while following international recommendations and scientific advances in the QI field. Supporting embedded implementation research within the programmes would promote a better understanding of the impeding and facilitating factors of each QI approach and lead to an improvement of their cost-effectiveness.

Acknowledgements We kindly acknowledge Dr Manzura Mirsaidova and Dr Mary White-Kaba for their inputs (data collection, preliminary analysis) during the initial steps of this review, Ms Stephanie Costa for proof-reading the successive drafts of this manuscript, and the various GIZ project teams who shared the information needed for this review.

Contributors SG performed the review and wrote the successive drafts. VB-A and $\mathrm{CB}$ reviewed and amended the drafts. All authors agreed on submitting the final version.

Funding GIZ funded both the research and the development of the manuscript.

Disclaimer The findings and conclusions presented in this article are those of the authors and do not necessarily represent the official position of GlZ.

Competing interests $\mathrm{SG}$ is an independent consultant contracted by $\mathrm{GlZ}$ to perform the review. VB-A and CB are GIZ staff.

Patient consent for publication Not required.

Provenance and peer review Not commissioned; externally peer reviewed. Data availability statement № additional data are available

Open access This is an open access article distributed in accordance with the Creative Commons Attribution Non Commercial (CC BY-NC 4.0) license, which permits others to distribute, remix, adapt, build upon this work non-commercially, and license their derivative works on different terms, provided the original work is properly cited, appropriate credit is given, any changes made indicated, and the use is non-commercial. See: http://creativecommons.org/licenses/by-nc/4.0/.

\section{REFERENCES}

1. Kassebaum NJ, Barber RM, Bhutta ZA, et al. Global, regional, and national levels of maternal mortality, 1990-2015: a systematic analysis for the global burden of disease study 2015. Lancet 2016;388:1775-812.

2. Wang $\mathrm{H}$, Bhutta ZA, Coates MM, et al. Global, regional, National, and selected subnational levels of stillbirths, neonatal, infant, and under-5 mortality, 1980-2015: a systematic analysis for the global burden of disease study 2015. Lancet 2016;388:1725-74.

3. Countdown to 2030 Collaboration. Countdown to 2030: tracking progress towards universal coverage for reproductive, maternal, newborn, and child health. Lancet 2018;391:1538-48.

4. Bailey PE, Andualem W, Brun M, et al. Institutional maternal and perinatal deaths: a review of 40 low and middle income countries. BMC Pregnancy Childbirth 2017;17:295.

5. Austin A, Langer A, Salam RA, et al. Approaches to improve the quality of maternal and newborn health care: an overview of the evidence. Reprod Health 2014;11(Suppl 2):S1.

6. Raven J, Hofman J, Adegoke A, et al. Methodology and tools for quality improvement in maternal and newborn health care. Int $J$ Gynaecol Obstet 2011;114:4-9.

7. World Health Organization. WHO | standards for improving quality of maternal and newborn care in health facilities. WHO, 2016. Available: http://www.who.int/maternal child adolescent/ documents/improving-maternal-newborn-care-quality/en/ [Accessed 20 Jan 2018].

8. Geneva: World Health Organization. WHO | Handbook for national quality policy and strategy. WHO, 2018. Available: http://www.who. int/servicedeliverysafety/areas/qhc/nqps_handbook/en/ [Accessed 20 Jun 2019].

9. Kruk ME, Gage AD, Arsenault C, et al. High-Quality health systems in the sustainable development goals era: time for a revolution. Lancet Glob Health 2018;6:e1196-252.

10. Berwick D, Snair M, Nishtar S. Crossing the global health care quality chasm: a key component of universal health coverage. JAMA 2018;320:1317-8.

11. Syed SB, Leatherman S, Mensah-Abrampah N, et al. Improving the quality of health care across the health system. Bull World Health Organ 2018;96:799.

12. Kickbusch I, Franz C, Holzscheiter A, et al. Germany's expanding role in global health. The Lancet 2017;390:898-912.

13. WHO. Health in 2015: from MDGs to SDGs. WHO. Available: http:// www.who.int/gho/publications/mdgs-sdgs/en/ [Accessed 21 Jan 2019].

14. TRACKING SUPPORT FOR THE MDGS. Maternal, Newborn and Child Health Muskoka Initiative - Germany. Available: https://iif.un. org/content/maternal-newborn-and-child-health-muskoka-initiativegermany [Accessed 18 Jan 2019].

15. Deutsche Gesellschaft für Internationale Zusammenarbeit (GIZ) $\mathrm{GmbH}$. Germany's contribution to the G8 Muskoka Initiative on Maternal, Newborn and Child Health. Progress report $2011-2015$. Berlin, Germany: : Federal Ministry for Economic Cooperation and Development (BMZ), 2017. Available: https://www.bmz.de/en/ zentrales_downloadarchiv/themen_und_schwerpunkte/gesundheit/ Germany_contribution_Muskoka-Initiative.pdf

16. German Federal Ministry for Economic Cooperation and Development (BMZ). BMZ initiative on Rights-based family planning and maternal health. fed. Minist. Econ. coop. DEV. Available: http:// health.bmz.de/en/healthportal/what we do/Reproductive-maternaland-child-health/policies_and_concepts/BMZ_Initiative_FP_MH/ index.html [Accessed 3 Dec 2018].

17. Munir K, Worm I. Health systems strengthening in German development cooperation: making the case for a comprehensive strategy. Global Health 2016;12:81.

18. Board on Global Health, Institute of Medicine, The National Academies of Sciences, Engineering, and Medicine. Improving quality of care in low- and middle-income countries, workshop summary. Washington, DC: National Academies Press, 2015.

19. Rowe AK, Rowe SY, Peters DH, et al. Effectiveness of strategies to improve health-care provider practices in low-income and middle-income countries: a systematic review. Lancet Global Health 2018;6:e1163-75.

20. World Health Organization. Human reproduction programme - Research for impact, Alliance for Health Policy ans Systems Research. WHO | Programme reporting standards for sexual, reproductive, maternal, newborn. child and adolescent health, 2017. Available: http://prs.srhr.org/ [Accessed 29 Jan 2019].

21. Schwerdtle P, Morphet J, Hall H. A scoping review of mentorship of health personnel to improve the quality of health care in low and middle-income countries. Global Health 2017;13. 
22. Gagliardi AR, Perrier L, Webster F, et al. Exploring mentorship as a strategy to build capacity for knowledge translation research and practice: protocol for a qualitative study. Implementation Sci 2009;4.

23. Hirano H. 5 S for Operators: 5 Pillars of the Visual Workplace. Taylor \& Francis, 1996.

24. Take N, Byakika S, Tasei $\mathrm{H}$, et al. The effect of $5 \mathrm{~S}$-continuous quality improvement-total quality management approach on staff motivation, patients' waiting time and patient satisfaction with services at hospitals in Uganda. J Public Health Afr 2015;6:486.

25. Pujo P, Pillet M. Control by quality: proposition of a typology. Qual Assur 2001;9:99-125.

26. Necochea E, Tripathi V, Kim Y-M, et al. Implementation of the Standards-Based management and recognition approach to quality improvement in maternal, newborn, and child health programs in low-resource countries. Int J Gynaecol Obstet 2015;130 Suppl 2:S17-S24.

27. Federal Ministry for Economic Cooperation and Development. Improving health care system-wide - Approaches in Morocco and Yemen. Dtsch. Ges. Für Int. Zusammenarbeit GIZ GmbH, 2012. Available: http://health.bmz.de/ghpc/case-studies/QualityImprovement/QIP_EN_short.pdf [Accessed 1 Feb 2019].

28. Danel I, Graham WJ, Boerma T. Maternal death surveillance and response. Bull World Health Organ 2011;89:779-80.

29. Goldenberg RL, McClure EM, Saleem S. Improving pregnancy outcomes in low- and middle-income countries. Reprod Health $2018 ; 15$.

30. WHO Regional Office for Europe. Donor coordination and a sector wide approach to health (swap), 2019. Available: http://www. euro.who.int/en/health-topics/Health-systems/health-systemsgovernance/activities/donor-coordination-and-a-sector-wideapproach-to-health-swap [Accessed 15 Jun 2019].

31. Munabi-Babigumira S, Glenton C, Lewin S, et al. Factors that influence the provision of intrapartum and postnatal care by skilled birth attendants in low- and middle-income countries: a qualitative evidence synthesis. Cochrane Database Syst Rev 2017;9.

32. Gabrysch S, Campbell OMR. Still too far to walk: literature review of the determinants of delivery service use. BMC Pregnancy Childbirth 2009;9:34.

33. Sharma G, Mathai M, Dickson KE, et al. Quality care during labour and birth: a multi-country analysis of health system bottlenecks and potential solutions. BMC Pregnancy Childbirth 2015;15:S2.

34. Gunawardena N, Bishwajit G, Yaya S. Facility-Based maternal death in Western Africa: a systematic review. Front Public Health 2018;6.

35. Say L, Chou D, Gemmill A, et al. Global causes of maternal death: a who systematic analysis. The Lancet Global Health 2014;2:e323-33.

36. ten Hoope-Bender P, de Bernis L, Campbell J, et al. Improvement of maternal and newborn health through midwifery. The Lancet 2014;384:1226-35.

37. Horton R, Astudillo O. The power of midwifery. Lancet 2014;384:1075-6.

38. WHO. Health workforce at the 144th session of the executive board WHO, 2019. Available: http://www.who.int/hrh/news/2019/hrh-ateb144th/en/ [Accessed 23 Jan 2019].

39. Alkema L, Chou D, Hogan D, et al. Global, regional, and national levels and trends in maternal mortality between 1990 and 2015, with scenario-based projections to 2030: a systematic analysis by the un maternal mortality estimation Inter-Agency group. Lancet 2016;387:462-74.

40. Rajkotia Y. Beware of the success cartel: a plea for rational progress in global health. BMJ Glob Health 2018;3:e001197.

41. Mumtaz Z, Ellison GTH, Ferguson A, et al. A call for transparency in the evaluation of global maternal health projects. Lancet 2016;388:461.

42. Kågesten $A E$, Tunçalp Özge, Portela $A$, et al. Programme reporting standards (PRS) for improving the reporting of sexual, reproductive, maternal, newborn, child and adolescent health programmes. BMC Med Res Methodol 2017;17:117. 